\title{
Aplikasi Pencarian Bengkel Aktif dengan Google Maps API Berbasis Web
}

\author{
Sitti Aisa \\ Teknik Informatika STMIK DIPANEGARA \\ Email: sitti.aisa@dipanegara.ac.id
}

\begin{abstract}
Abstrak. Peningkatan pengguna kendaraan di Kota Makassar sebagian besar membutuhkan perawatan dan perbaikan saat kendaraan mengalami masalah. Mencari lokasi bengkel terdekat dari tempat dimana kendaraan mengalami masalah adalah salah satu hal yang paling banyak dibicarakan saat ini. Banyaknya bengkel yang tersebar di Kota Makassar tidak sebanding dengan informasi tentang lokasinya. Untuk memudahkan masyarakat dalam mencari dan menjangkau suatu lokasi dari suatu bengkel maka proses pencarian lokasi dapat dilakukan dengan memanfaatkan teknologi dari Google Maps API dimana kita dapat melihat lokasi bengkel tersebut. Metode penelitian berupa metode waterfall dimana didalamnya terdiri beberapa proses yaitu menentukan ruang lingkup aplikasi, menganalisis, membuat desain, menerapkan, menguji coba serta menggunakan aplikasi. Oleh karena itu diperlukan suatu aplikasi berbasis web yang dapat memberikan informasi mengenai lokasi bengkel yang masih buka yang ada di sekitar kita, yang nantinya memudahkan kita untuk mengetahui bengkel mana yang masih buka dan terdekat dengan lokasi kita. Hasil dari penelitian ini adalah aplikasi yang memberikan kemudahan pengendara untuk mencari lokasi bengkel terdekat dari titik lokasinya sehingga memudahkan membawa kendaraannya untuk bisa diperbaiki lebih cepat.
\end{abstract}

\section{Kata Kunci: Bengkel, Google Maps, Berbasis Web}

\begin{abstract}
The increase in vehicle users in Makassar City mostly requires maintenance and repairs when vehicles experience problems. Finding the location of the nearest repair shop from the place where the vehicle is having problems is one of the most talked about things today. The number of workshops scattered in Makassar City is not comparable with information about their location. To make it easier for people to find and reach a location from a workshop, the location search process can be done by utilizing technology from the Google Maps API where we can see the location of the workshop. The research method is in the form of the waterfall method which consists of several processes, namely determining the scope of the application, analyzing, designing, implementing, testing and using the application. Therefore we need a web-based application that can provide information about the location of workshops that are still open around us, which will make it easier for us to find out which workshops are still open and the closest to our location. The result of this research is an application that makes it easy for motorists to find the location of the nearest repair shop from its location point, making it easier to bring their vehicle to be repaired faster.
\end{abstract}

Keywords: Workshop, Google Maps, website

\section{Pendahuluan}

Dengan semakin berkembangnya teknologi mobile berdampak terhadap akses informasi yang semakin mudah. Didukung oleh perkembangan teknologi smartphone yang semakin pesat dan semakin murah dengan jangkauan teknologi broadband yang semakin luas memungkinkan seseorang untuk mendapatkan informasi semakin mudah dan cepat (Slameto \& Pramono 2017).

Pengguna kendaraan bermotor di Indonesia semakin banyak. Dari data yang dikumpulkan oleh BPS, jumlah kendaraan di Indonesia pada tahun 2014 adalah sebanyak 114.209.266. Hal 
tersebut juga akan berbanding lurus dengan jumlah kerusakan kendaraan bermotor, dalam hal ini adalah masalah ban. Ban bocor atau kempes bukan hal yang bias diperkirakan. Selain itu, ban sendiri merupakan bagian penting dari kendaraan kita (Ramadhani \& Utama 2020).

Kota Makaknya pengguna kendaraan di memerlukan pemeliharaan dan perbaikan saat kendaraan mengalami masalah. Terjadinya kebocoran ban di tengah perjalanan sering dapat di sebabkan oleh banyak hal, seperti terkena benda tajam, usia ban terlalu tua ,bocor di bekas tambalan, atau bisa disebabkan oleh lainnya (Ramadhani \& Utama 2020).

Pencarian suatu lokasi merupakan satu Makassar tentu masih akan kesulitan untuk mencari tempat atau alamat yang diinginkan masalah yang paling banyak dibahas saat ini. Banyaknya bengkel yang tersebar di Kota Makassar tidak sebanding dengan informasi tentang lokasinya. Agar mempermudah masyarakat dalam mencari dan menjangkau suatu lokasi dari bengkel, proses pencarian lokasi dapat dilakukan dengan memanfaatkan teknologi dari Google Maps API yang mana kita dapat melihat lokasi bengkel tersebut. Google Maps merupakan aplikasi peta bawaan dari semua perangkat android dan dapat diakses secara gratis oleh semua pengguna android. Google Maps menyediakan banyak fitur, salah satunya adalah pencarian rute dari suatu tempat ke tempat yang lain. Google Maps juga bisa diakses melalui mobile phone.(Dewantara, Hanafi, \& Nugraha 2018) (Minarni \& Yusdi 2015)

Bengkel adalah tempat yang sangat dibutuhkan para pengendara yang mengalami masalah pada kendaraanya, bagaimana ketika kendaraan kita tibatiba mengalami masalah di jalan? Pastinya kita segera mencari bengkel yang ada di sekitar jalan yang kita lewati saat itu. Bagaimana jika kita tidak mengetahui pasti lokasi bengkel yang ada di sekitar kita? Bagaimana jika kita mengetahui lokasi bengkel tapi bengkel tersebut tutup?

Contoh sederhanya misalkan kita ingin membuat Sistem Informasi Geografis (SIG), dengan memanfaatkan Google Maps API, kita bisa membuat SIG tanpa perlu memikirkan Peta, dengan menggunakan Google Maps dan memanggil fungsi-fungsi yang dibutuhkan seperti menampilkan peta, menempatkan marker dan sabagainya. Tujuan penelitian adalah merancang sebuah aplikasi pencarian bengkel aktif menggunakan google maps Api serta memberikan akses ke pengguna dalam mencari lokasi bengkel yang aktif dan berada didekat dari lokasi pengguna.

Hasil dari penelitian ini agar mampu memudahkan pengguna yang sedang mengalami kesulitan dijalan untuk bisa mencari bengkel terdekat dengan memanfaatkan aplikasi ini. Beberapa penelitian sebelumnya yang telah di teliti dengan memanfaatkan google maps yaitu saputro dkk, yang dilakukan pada tahun 2013 dimana dalam penelitiannya membahas mengenai pencarian rute terpendek untuk mengetahui tempat wisata yang ada di kota manado dengan memanfaatkan metode algoritma Dijkstra (Saputro 2013).

Ada juga penelitian yang dilakukan oleh Darwis dkk di tahun 2019 dimana pencarian lokasi bengkel mobil resmi menggunakan teknik pengolahan suara dan bahasa alami (Darwis, Pasaribu, and Surahman 2019). Serta penelitian yang dilakukan oleh Herli, dkk yang diterbitkan pada tahun 2015 dimana pencarian hotel berdasarkan rute terpendek dengan pemanfaatan algoritma Greedy (Herli, Raharjana, \& Soeparman 2015).

Tujuan dari penelitian adalah untuk membuat sebuah aplikasi berbasis web yang memudahkan pengendara untuk mencari bengkel terdekat dari titik lokasi keberadaan, sehingga dapat memudahkan untuk memperbaiki kendaraannya ketika sewaktu - waktu mengalami masalah di 
jalan, serta mengefisienkan waktu dalam pencarian bengkel.

\section{Landasan Teori \\ Google Maps}

Google maps adalah jasa peta gratis dan online yang disediakan oleh google yang dapat ditemukan di http://maps.google.com. Pada situs tersebut kita dapat melihat informasi geografis pada hamper semua wilayah dimuka bumi. Layanan google maps ini interaktif, karena didalamnya peta dapat digeser sesuai keinginan pengguna, mengubah tingkat zoom, serta mengubah tampilan peta. Google maps juga menawarkan peta yang dapat diseret dan gambar satelit untuk seluruh dunia, serta menawarkan rute perjalanan (Huda 2014).

Google Maps API merupakan aplikasi interface yang dapat diakses lewat javascript agar Google Maps dapat ditampilkan pada halaman web yang sedang kita bangung. Untuk dapat mengakses Google Maps, Kita harus melakukan pendaftaran Api Key terlebih dahulu dengan data pendaftaran berupa nama domain web yang kita bangun. Banyak sekali kegunaan google map untuk website yang kita buat, diantaranya dapat digunakan untuk menampilkan lokasi pemilik website ( pada about us ), lokasi event/kegiatan, atau dapat juga digunakan untuk aplikasi GIS berbasis web.

Pada Google Maps API terdapat 4 jenis pilihan model peta yang disediakan oleh Google, diantaranya adalah:

1. ROADMAP, ini yang saya pilih, untuk menampilkan peta biasa 2 dimensi

2. SATELLITE, untuk menampilkan foto satelit

3. TERRAIN, untuk menunjukkan relief fisik permukaan bumi dan menunjukkan seberapa tingginya suatu lokasi, contohnya akan menunjukkan gunung dan sungai

4. HYBRID, akan menunjukkan foto satelit yang diatasnya tergambar pula apa yang tampil pada ROADMAP (jalan dan nama kota) (Gufroni et al. 2013)

\section{Haversine Formula}

Teorema Haversine Formula adalah sebuah persamaan yang penting dalam bidang navigasi, untuk mencari jarak busur antara dua titik pada bola dari longitude dan latitude. Ini merupakan bentuk persamaan khusus dari trigonometri bola, law of habersines, mencari hubungan sisi dan sudut pada segitiga dalam bidang bola. (Yulianto 2015)

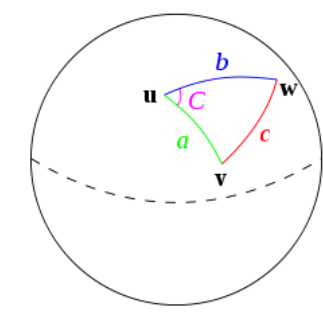

Gambar 1. Segitiga Bola Diselesaikan dengan Hukum Haversine Formula

Hukum haversine adalah semua persamaan yang digunakan berdasarkan bentuk bumi yang bulat (spherical earth) dengan menghilangkan faktor bumi itu sedikit elips (elipsodial factor). Ini merupakan kasus khusus dari formula umum dalam trigonometri bolo,hukum haversines, yang berkaitan dengan sisi sudut segituga bola. Dalam unit bola, sebuah "segitiga" pada permukaan bola didefenisikan sebagai lingkaranlingkaran besar yang menghubungkan tiga poin $\mathbf{u}, \mathbf{v}$,dan $\mathbf{w}$ pada bola. Jika panjang dari ketiga sisi adalah (dari u ke $\mathbf{v})$, b(dari u ke w) dan (dari $\mathbf{v}$ ke w), dan sudut-sudut yang berlawanan $\mathbf{C}$ dan $\mathbf{C}$. Maka hukum haversine menjadi:

Haversin $(c)=$ haversin $(a-b)+\sin (a) \sin (b)$ haversin $(C)$.

Haversine formula nantinya akan digunakan dalam perhitungan jarak antara dua titik GPS. Dalam hal ini adalah titk GPS user dan titik GPS tujuan, titik GPS ini berisikan latitide dan longitide, sehingga dapat menjadi kunci utama dalam perbandingan jarak pada penentuan lokasi bengkel terdekat. Berikut rumus haversine yang akan di implementassikan kedalam kasus ini:

Haversine $\left(\frac{\mathrm{d}}{\mathrm{R}}\right)=$ haversine $\left(\theta_{1}-\theta_{2}\right)+$ $\cos \left(\theta_{1}\right) \cos \left(\theta_{2}\right)$ haversine $\left(\chi_{2}-\chi_{1}\right)$

Dimana:

$\Theta_{1}=$ latitude dari titik 1 atau posisi user. 
$\theta_{2}=$ latitude dari titik 2 atau lokasi tujuan.

$\chi_{1}=$ longitude dari titik 1 atau posisi user.

$\chi_{2}=$ longitude dari titik 2 atau posisi lokasi tujuan.

$\mathrm{D}=$ Jarak antara dua titik.

$\mathrm{R}=$ Radius.

Dari perhitungan diatas, untuk menentukan jarak paling dekat dengan lokasi harus terdapat pembanding. Jadi harus terdapat banyak titik lokasi dan ditemukan jarak, barulah dibandingkan mana jarak terpendek. Untuk jalur jalan yang sebenarnya sesuai kondisi memanfaatkan google maps, lalu akan ditampilkan marker antara lokasi user dan lokasi tujuan serta informasi jalan mana saja yang di lalui, untuk perhitungan haversine akan dilakukan didalam query sql yang dikerjakan oleh system, dan hasilnya akan di jadikan sebuah JSON, sehingga aplikasi tidak bekerja dengan berat.

\section{PHP}

PHP adalah bahasa tambahan untuk HTML dan digunakan untuk membuat aplikasi dinamis yang memungkinkan pemrosesan data dan pemrosesan data. Semua tata bahasa yang diberikan akan dijalankan sepenuhnya di sistem komputer sebagai penyedia layanan, dan hanya hasilnya yang akan dikirim ke web browser. Script adalah bahasa berupa kode yang dapat meningkatkan fungsionalitas sebuah website yang ditempatkan dan diproses di server. Hasilnya akan dikirim ke klien, di mana pengguna menggunakan browser.(Anugraha, Angriawan, and Mashud 2020)

\section{Metode Penelitian}

Pada prinsipnya, metode penelitian menjadi kesatuan metode untuk memecahkan masalah secara logis dan sistematis serta dukungan dari datadata yang valid. Untuk penelitian ini proses yang dilakukan di bagi menjadi 6 tahapan yang tergambar dibawah ini :

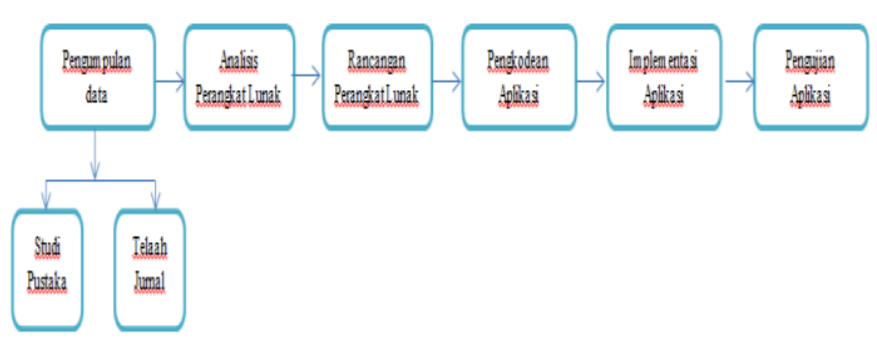

Gambar 2. Alur Penelitian

Adapun tahapan-tahapan yang dilakukan dalam penelitian yaitu sebagai berikut:

Pengumpulan data

Pada tahap ini dilakukan proses untuk mengumpulkan data - data yang relevan dan terkait dengan penelitian yaitu mencari data-data bengkel yang ada dan juga informasi lokasi bengkel

Analisis perangkat lunak

Pada tahap ini analisis dilakukan dengan memperhatikan permasalahan dan tujuan dibangunnya Aplikasi Pencarian Bengkel Aktif Di Wilayah Kota Makassar Berbasis Google Maps API

Rancangan perangkat lunak

Pada tahap ini membuat rancangan aplikasi pencarian bengkel aktif di wilayah Kota Makassar yang diinginkan pada tahap analisis

Pengkodean Aplikasi

Pada tahap ini membuat kode program aplikasi pencarian bengkel aktif di wilayah Kota Makassar dengan menggunakan bahasa pemrograman php Pengujian aplikasi

Untuk mengetahui adanya kesalahan pada logika yang dirancang maka dilakukan uji coba dan bila terjadi kesalahan dilakukan perbaikan. Evaluasi dilakukan untuk menguji fungsi- fungsi dari aplikasi pencarian bengkel aktif di wilayah Kota Makassar

Implementasi

Pada tahap ini implementasi dilakukan untuk menerapkan aplikasi yang telah dirancang melalui proses pengujian sistem. 


\section{Hasil Penelitian}

Perancangan sistem

Langkah awal perancangan dalam pembuatan sistem informasi pengarsipan adalah membuat dokumentasi dengan menggunakan UML (Unfield Modelling Languange), dengan menggunakan beberapa buah diagram, yaitu : use case diagram kemudian membuat activity diagram, sequence diagram dan yang terakhir class diagram yang menunjukan setiap aktifitas program atau sistem.

\section{Use Case Diagram}

Use case diagram berfungsi untuk menjalankan sistem jika dilihat menurut pandangan orang yang berada di luar sistem (actor). Pada sistem ada beberapa actor yang terlibat dimana actor tersebut yang menggunakan sistem pencarian bengkel aktif terdekat(Mulyani 2017).

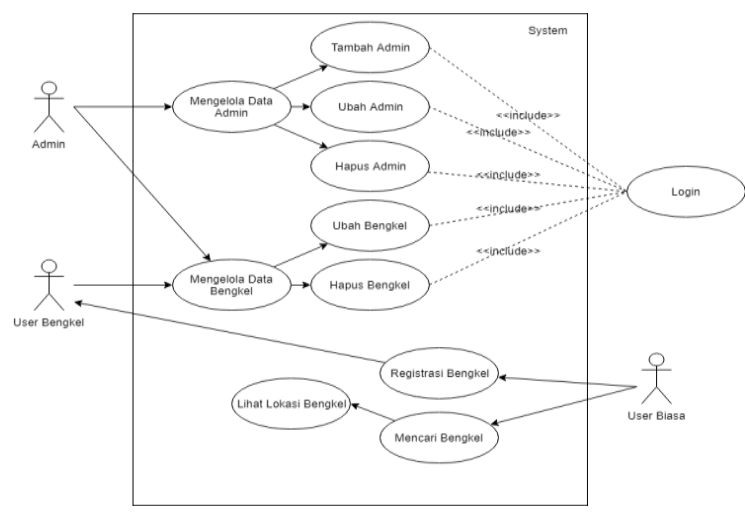

Gambar 3 Use Case Diagram

Pada gambar 3 di jelaskan ada 3 aktor yaitu admin, user bengkel dan user biasa, dimana admin dapat login dengan beberapa pekerjaan yaitu mengelola data bengkel, mengelola data admin dan lainnya. Dimana user biasa melakukan registrasi, mencari bengkel dan lihat lokasi bengkel.

\section{Activity Diagram}

Activty diagram ini mengembangkan proses bisnis dan urutan aktivitas dalam sebuah proses. Activity diagram untuk aplikasi ini yang berlangsung pada activity diagram menampilkanp proses jalannya sistem informasi untuk lebih memperjelas activity diagram untuk use case menampilkan proses jalannya sistem, lebih jelasnya dapat dilihat gambar di bawah ini :

\section{Activity Diagram Admin}

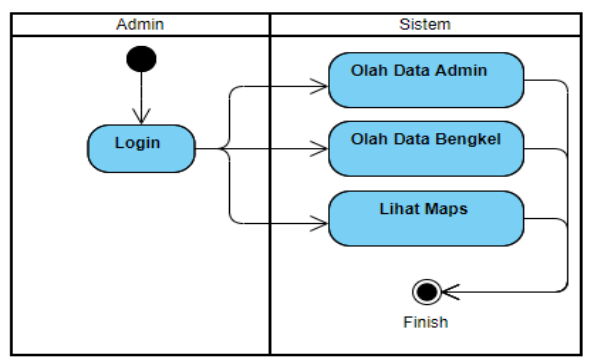

Gambar 4 Activity Diagram Admin

Pada gambar 4 adalah activity diagram untuk admin, dimana pekerjaan terdiri dari olah data admin, olah data bengkel serta lihat maps.

Activity Diaram User

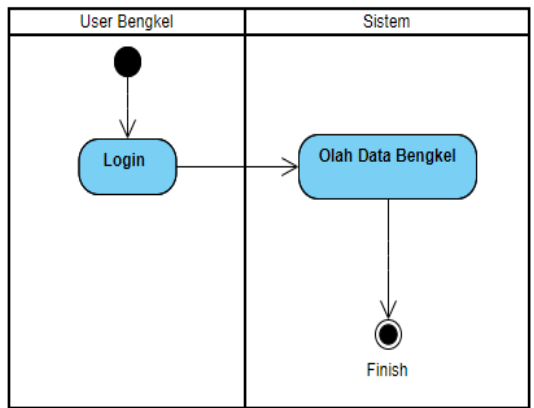

Gambar 5. Activity Diagram User Bengkel Pada gambar 5 adalah activity diagram untuk user bengkel, dimana pekerjaannya yaitu olah data bengkel.

Activity Diagram User Biasa

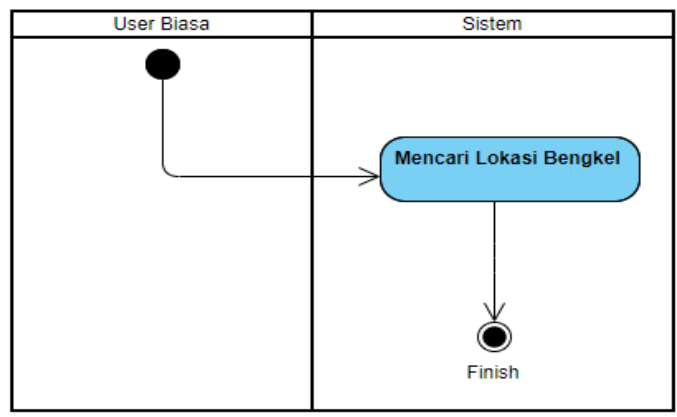

Gambar 6 : Activity Diagram User Biasa

Pada gambar 6 adalah activity diagram untuk user biasa, dimana 
pekerjaannya dalam system yaitu mencari lokasi bengkel.

\section{Sequence Diagram}

Sequence diagram adalah suatu diagram yang memperlihatkan atau menampilkan interaksi-interaksi antar objek di dalam sistem yang disusun pada sebuah urutan atau rangkaian waktu. Interaksi antar objek tersebut termasuk pengguna, display, dan sebagainya berupa meng-create data dan sebagainya.

\section{Sequence Diagram Admin}

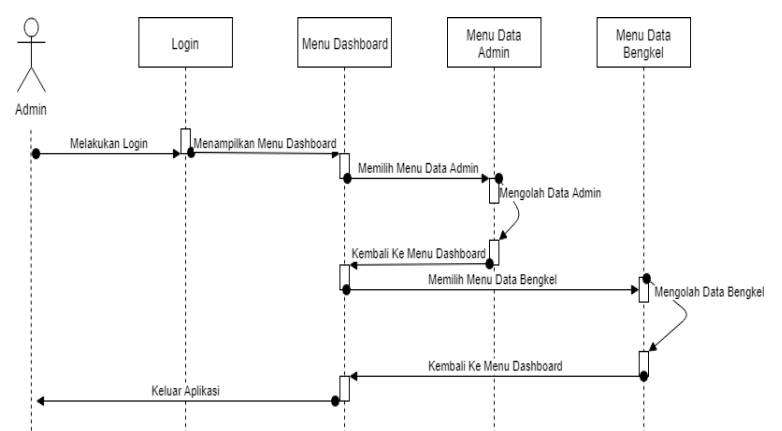

Gambar 7 Sequence Diagram Admin

Pada gambar 7 terdapat sequence diagram admin, dimana admin dapat login kemudian masuk di beranda utama lalu masuk ke menu data admin dimana dapat menambah dan mengedit admin serta bisa ke menu data bengkel.

\section{Sequence Diagram User Bengkel}

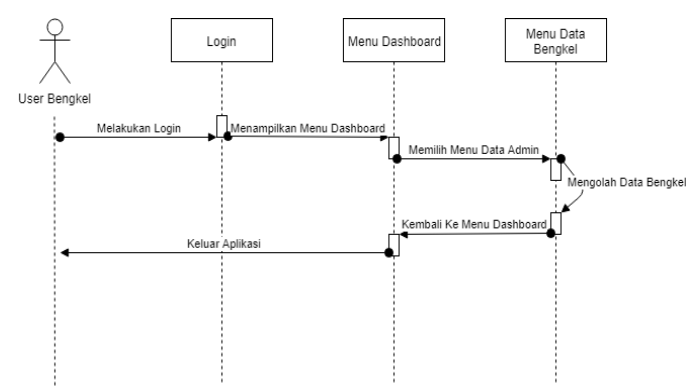

\section{Gambar 8 Sequence Diagram User Bengkel}

Pada gambar 8 terdapat sequence diagram user bengkel, dimana user dapat login kemudian masuk di beranda utama lalu masuk ke menu data bengkel dimana didalamnya dapat mengolah data bengkel yang ada.

\section{Sequence Diagram User Biasa}

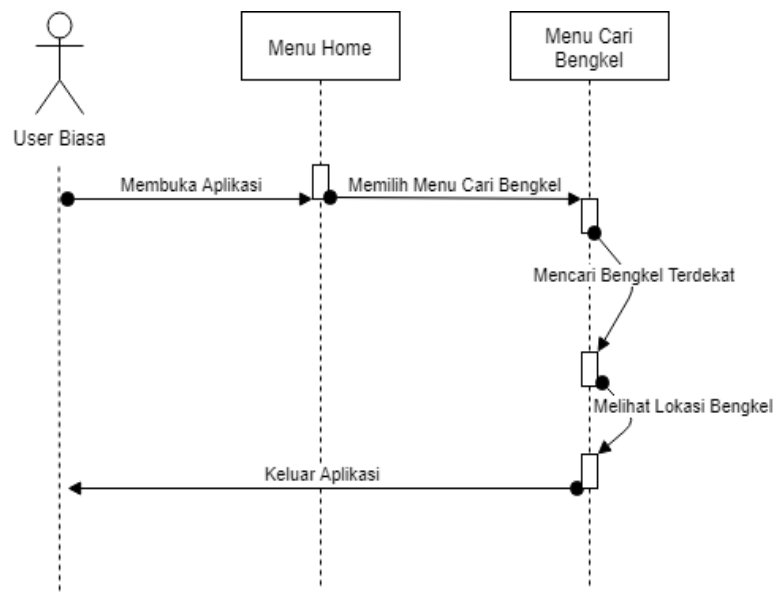

Gambar 9 Sequence Diagram User Biasa

Pada gambar 9 terdapat sequence diagram user biasa dimana dapat langsung mengakses aplikasi berbasis web dengan mengetik urlnya di web browser kemudian mencari bengkel terdekat dari titik lokasi user kemudian melihat lokasi dari bengkel terdekat.

\section{Pembahasan}

Metode Perhitungan Haversine Formula Rumus haversine merupakan rumus yang sering digunakan dalam navigasi, rumus Haversine digunakan untuk menghitung jarak antara titik di permukaan bumi menggunakan garis lintang (longitude) dan garis bujur (lattitude) sebagai variabel inputan. Haversine formula adalah persamaan penting pada navigasi, memberikan jarak lingkaran besar antara dua titik pada permukaan bola (bumi) berdasarkan bujur dan lintang. Dengan mengasumsikan bahwa bumi berbentuk bulat sempurna dengan jari-jari R 6.367, $45 \mathrm{~km}$, dan lokasi dari 2 titik di koordinant bola (lintang dan bujur) masing-masing adalah lon1, lat1, dan lon2, lat2, maka rumus Haversine dapat ditulis dengan persamaan sebagai berikut:

$$
\begin{aligned}
& \mathrm{x}=(\text { lon2-lon } 1) * \cos ((\text { lat1+lat2 }) / 2) ; \\
& \mathrm{y}=(\text { lat2-lat } 1) ;
\end{aligned}
$$


$d=\operatorname{sqrt}\left(x^{*} x+y^{*} y\right) * R$

Keterangan:

$\mathrm{x}=$ Longitude (Lintang)

$\mathrm{y}=$ Lattitude (Bujur)

$\mathrm{d}=$ Jarak

$\mathrm{R}=$ Radius Bumi $=6371 \mathrm{~km}$

$\mathrm{B}=1$ derajat $=0.0174532925$

radian

Implementasi Aplikasi

Halaman Login

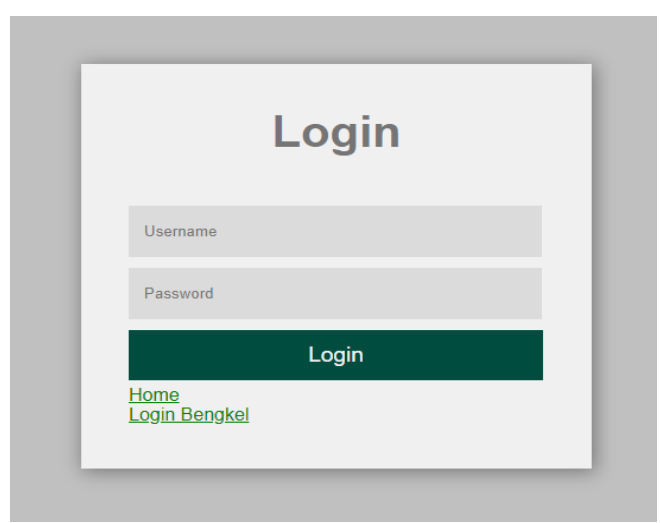

Gambar 10 Halaman login dari aplikasi

Pada gambar 10 terdapat halaman login utama dari aplikasi dimana digunakan untuk admin dan user bengkel untuk masuk ke aplikasi. Jika login berhasil maka langsung menuju ke dashboard atau beranda utama dari aplikasinya.

\section{Halaman Data Bengkel}

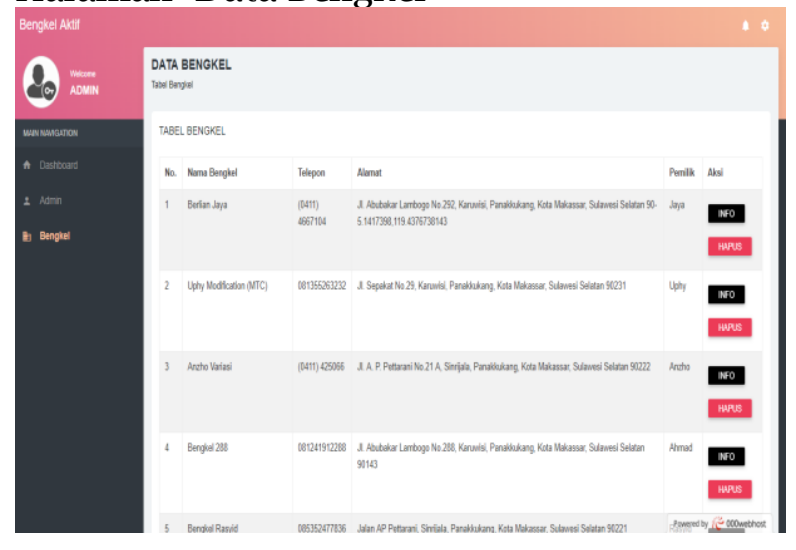

Gambar 11 Halaman Form Data Bengkel Pada gambar 11 terdapat halaman data bengkel d login utama dari aplikasi dimana digunakan untuk admin dan user bengkel untuk masuk ke aplikasi. Jika login berhasil maka langsung menuju ke dashboard atau beranda utama dari aplikasinya.

Halaman Form Registrasi Bengkel
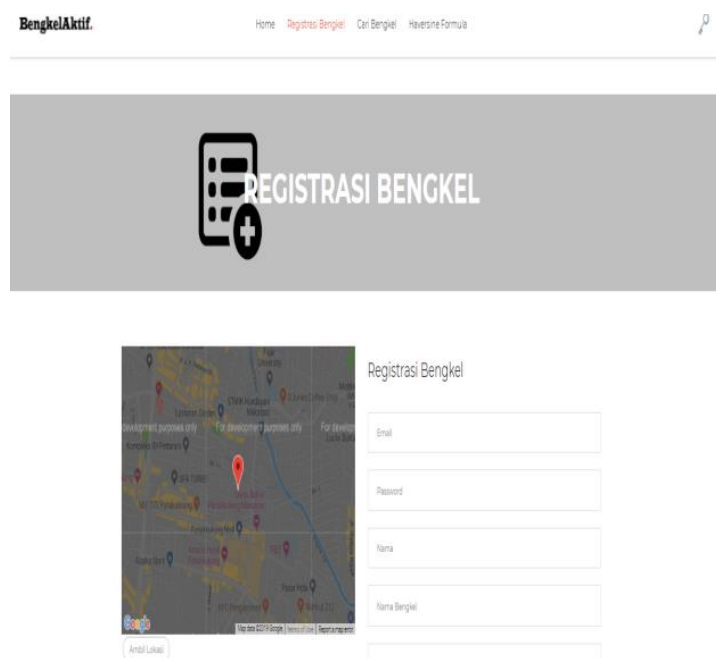

\section{Gambar 12 Halaman Form Registrasi Bengkel}

Pada gambar 12 terdapat halaman form registrasi bengkel dimana setelah berhasil login masuk ke beranda utama lalu masuk ke halaman.

\section{Halaman Form Dashboard User Bengkel}

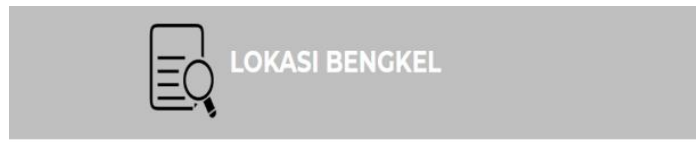

\section{Gambar 13 Halaman Form Dashboard} User Bengkel

Pada gambar 13 terdapat halam form user bengkel dimana didalamnya terdapat lokasi atau titik tempat bengkel berada. 


\section{Halaman Form Cari Bengkel}
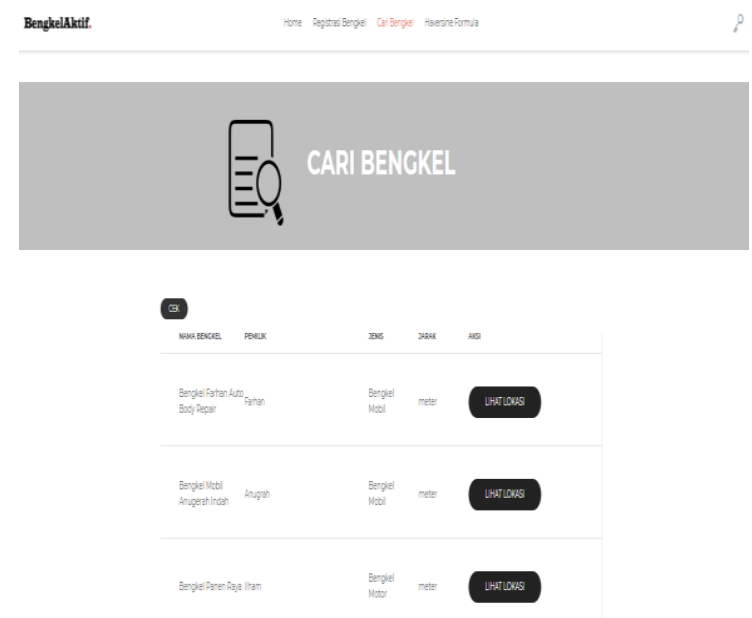

Gambar 14 Halaman Form cari bengkel

Pada gamba 14 terdapat halaman form untuk cari bengkel. Dimana ketika diketik nama bengkelnya otomatis akan muncul.

Halaman Form Perhitungan Metode Haversine

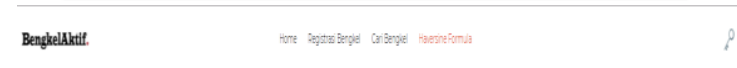
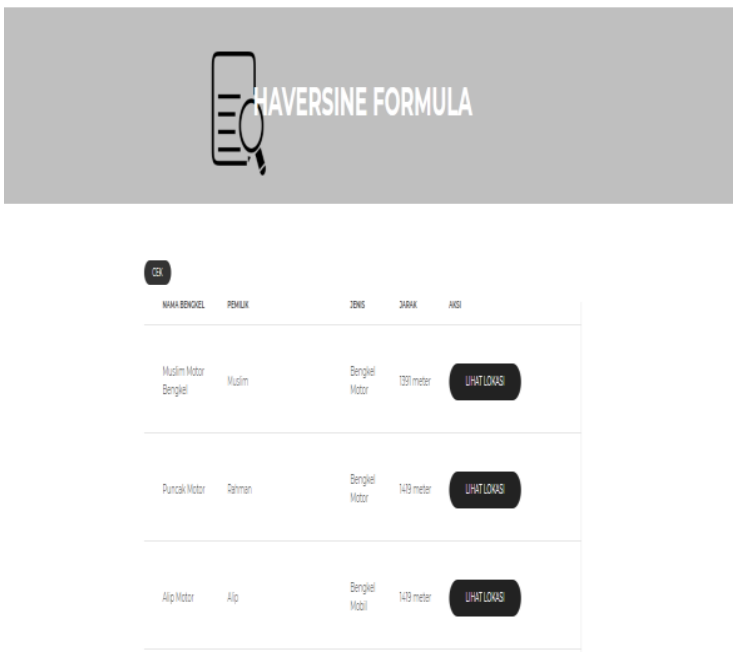

\section{Gambar 15 Halaman Form Perhitungan Metode Haversine.}

Pada gambar 15 terdapat halaman form perhitungan metode haversine dimana terdapat nama bengkel lalu jenis bengkel serta jarak.

\section{Kesimpulan}

Sistem ini dapat menganalisa jarak terpendek dari dua buah titik menggunakan metode haversine formula. Aplikasi ini dapat memberikan solusi kepada masyarakat untuk mencari lokasi bengkel yang aktif (buka) saat kendaraan mengalami masalah. Pengujian yang dilakukan yaitu dengan Metode Black Box, dimana metode ini mengukur fungsionalitas dari setiap form yang ada pada aplikasi yang telah di ujikan

\section{Daftar Pustaka}

Anugraha, Nurhajar, Randy Angriawan, \& Mashud Mashud. 2020. 'Sistem Informasi Geografis Layanan Publik Lingkup Kota Makassar Berbasis Web'. DoubleClick: Journal of Computer and Information Technology 4(1): 3540.

Darwis, Dedi, A Ferico Pasaribu, \& Ade Surahman. $2019 . \quad$ 'Sistem Pencarian Lokasi Bengkel Mobil Resmi Menggunakan Teknik Pengolahan Suara Dan Pemrosesan Bahasa Alami'. Jurnal Teknoinfo 13(2): 71-77.

Dewantara, Helmy, Mukhtar Hanafi, \& Setiya Nugraha. 2018. 'Aplikasi Pencari Tambal Ban Area Magelang Berbasis Android Dengan Menggunakan Metode Haversine'. Jurnal Komtika (Komputasi dan Informatika) 2(1): 38-48.

Gufroni, Acep Irham, Andi Nur Rachman, Nurul Hiron, \& Yaya Abdul Malik. 2013. 'Implementasi Google Maps API Dalam Aplikasi Mobile Penghitung Jarak Aman Dari Dampak Kemungkinan Letusan Gunung Galunggung'.

Herli, Audrey Maximillian, Indra Kharisma Raharjana, \& 
Purbandini Soeparman. 2015. 'Sistem Pencarian Hotel Berdasarkan Rute Perjalanan Terpendek Dengan Mempertimbangkan Daya Tarik Wisata Menggunakan Algoritma Greedy'. Journal of Information Systems Engineering and Business Intelligence 1(1): 9-16.

Huda, M. 2014. 'Pengenalan Dan Cara Kerja Google Maps'. Tersedia http://www. mkhuda. com.[16 Oktober 2016].

Ika, Desy Ika Puspitasari, Budi Ramadhani, \& Tri Angga Tegar Utama. 2020. 'Pemanfaatan WebGIS Untuk Pemetaan Lokasi Dan Kondisi Rambu Lalu Lintas Kota Banjarbaru'. Digital Zone: Jurnal Teknologi Informasi Dan Komunikasi 11(2): 311-23.

Minarni, Minarni, \& Yovi Febri Yusdi. 2015. 'Sistem Informasi Geografis PARIWISata Kota Padang Menggunakan Application Programming Interface (API) Google Maps Berbasis WeB'. Jurnal Teknoif 3(1).
Mulyani, Sri. 2017. Metode Analisis Dan Perancangan Sistem. Abdi Sistematika.

Saputro, Stevian Suryo. 2013. 'Perancangan Aplikasi GIS Pencarian Rute Terpendek Peta Wisata Di Kota Manado Berbasis Mobile WEB Dengan Algoritma Dijkstra'. Teknik Informatika, Universitas Dian Nuswantoro, Semarang.

Slameto, Andika Agus, \& Eko Pramono. 2017. 'Inovasi Peta Digital Lokasi Bengkel Tambal Ban Untuk Smartphone'. Respati 12(3).

Yulianto, Whelly. 2015. 'Menentukan Jarak Terdekat Hotel Dengan Metode Haversine Formula'. 